\title{
Analogue experiments on the rise of large bubbles through a solids-rich suspension: a "weak plug" model for Strombolian eruptions
}

\author{
Oppenheimer J. ${ }^{*}$, Capponi A. ${ }^{2}$, Cashman K. V. ${ }^{3}$, Lane S. J. ${ }^{2}$, Rust A. C. ${ }^{3}$, James M. R. ${ }^{2}$ \\ 1. Lamont-Doherty Earth Observatory with Columbia University, New York, USA; 2. Lancaster \\ Environment Centre, Lancaster University, Lancaster, UK; 3. Department of Earth Sciences, \\ University of Bristol, Bristol, UK. \\ * Corresponding author: Julie Oppenheimer. Email address: jo0231@my.bristol.ac.uk \\ Lamont-Doherty Earth Observatory with Columbia University, \\ 61 route 9 W - PO Box 1000, Palisades, NY 10964, USA
}

\section{Abstract}

Physical interactions between bubbles and crystals affect gas migration and may play a major role in eruption dynamics of crystal-rich magmas. Strombolian eruptions represent an end member for bubble-crystal interactions, in which large bubbles (significantly larger than the crystal size) rise through a crystal-rich near-surface magma. Indeed, volcanoes that produce Strombolian eruptions often generate ejecta with $>30$ vol\% (often $>45$ vol\%) average crystallinity. At Stromboli Volcano, Italy, average crystallinity can reach 55 vol\%, which is approaching the eruptibility limit for magmas. At such high crystallinities the solids interact mechanically with each other and with bubbles. This complex rheology complicates the two-phase (liquid-gas) slug flow model often applied to Strombolian eruptions. To examine the effect of crystals on bubble rise, we performed analogue experiments in which large bubbles rise in a vertical tube filled with silicone oil and polypropylene particles. The particles have a slightly lower density than the oil, and therefore form a layer of oil + particles at the upper surface. We varied surface pressure, particle volume fraction, length of the particle-bearing cap, and bubble size to examine the ways in which these parameters influence Strombolian-type eruptions. We show that in experiments, suspended solids begin to affect bubble rise dynamics at particle volume fractions as low as 30 vol\% (or, when divided by the random close packing value, a normalized particle fraction $\varphi=0.64$ ). Bubbles in experiments with higher particle contents deform as they rise and burst through a small aperture, generating surface fountains that begin abruptly and decay slowly, and longer-lasting acoustic signals of lower amplitude than in crystal-poor experiments. In the experiments, particle fractions $>37$ vol\% $(\varphi>0.80)$ generated strong deformations on fast-expanding bubbles that applied a high stress on the cap, but they trapped bubbles that were less overpressured. Qualitatively, the gas release behavior observed in particle-rich experiments is consistent with observations of Strombolian eruptions. Moreover, we estimate that the observed crystallinity of pyroclasts at Stromboli volcano represents $\varphi>0.8$. From this we suggest a "weak plug" model for Strombolian eruptions that evolves towards a low-viscosity 
equivalent of Vulcanian-style plug failure with a more crystalline, stronger, and less permeable plug. Importantly, this model allows the rise of several bubbles in the conduit at the same time and suggests that longer-lasting, more pulsatory and complex eruptions may reveal an increase in nearsurface crystallinity, shedding some light on changing conduit conditions that could help determine the different gas rise regimes involved in passive degassing, puffing, and different expressions of Strombolian explosions.

Keywords: Eruption dynamics; Stromboli; Source mechanism; three-phase magma; Conduit processes; Analogue experiments

\section{Introduction}

Strombolian eruptions are generally small and frequent, but can be associated with dangerous paroxysms, as demonstrated by recent explosions at Stromboli volcano, Italy (2019), and Fuego, Guatemala (2018). In this way, Strombolian eruptions provide direct (and often long-term) insight into changes in conduit conditions that precede and follow hazardous activity. Nevertheless, while Strombolian eruptions are intensively studied (primarily at Stromboli volcano), our interpretation of their source dynamics is hindered by a major flaw: the traditional two-phase model for Strombolian eruptions neglects the effect of crystals on bubble rise, despite the crystal-rich nature of pyroclasts associated with this activity.

Most models for Strombolian eruptions consider Taylor bubbles (slugs) ascending in a Newtonian liquid (e.g. Seyfried and Freundt, 2000; Blackburn et al., 1976; Vergniolle, 1998; Del Bello et al., 2012; Hasan et al., 2019). As slugs expand during ascent, their internal pressure exceeds that in the magma column above; this self-sustained bubble expansion accelerates the overlying liquid to accommodate the gas volume change and increases bubble overpressure at burst (James et al., 2008, 2009; Del Bello et al., 2012; Lane et al., 2013).

However, pyroclasts ejected by many Strombolian eruptions have moderate to high crystallinities. For example, pyroclasts contain $>55$ vol\% crystals at Etna, Italy (Polacci et al., 2006; Giordano et al., 2010; Edwards et al., 2018); 30-40 vol\% at Yasur, Vanuatu (Metrich et al., 2011); $45-55$ vol\% at 
61 Stromboli, Italy (Metrich et al., 2010; Landi et al. 2011). This evidence has motivated models

62 involving more complex near-surface processes including magma mingling (Lautze and Houghton,

63 2005), conduit convection (Landi et al., 2004, 2011; Beckett et al., 2014), and near-surface

64 rheological changes (e.g. Gurioli et al., 2014; Del Bello et al., 2015; Gaudin et al., 2017).

Scaled analogue experiments with gas slugs ascending from a low to high viscosity Newtonian liquid

66 have explored the effects of a near-surface viscous transition on slug flow in a cylindrical conduit

67 (Del Bello et al., 2015; Capponi et al., 2016, 2017). These investigations proposed three geometrical

68 configurations of the slug-cap interactions based on the viscosity of the upper layer (the viscous

69 "cap") and the size of the cap relative to the bubble volume (Figure 1). Longer and more viscous caps

70 impede bubble expansion (hence compress bubbles) below the cap, which affects pressure signals

71 recorded at the base of the experiment, burst processes, and acoustic signals at the surface.

\section{Low-viscosity High-viscosity (plug)}

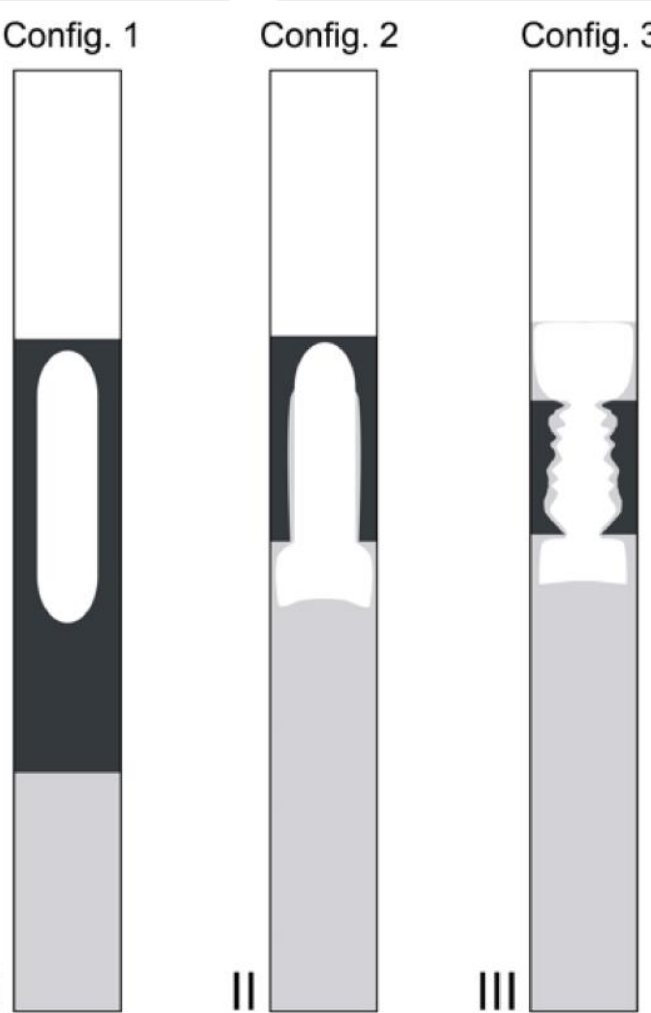

Figure 1: Flow configurations in Capponi et al. (2016, reprinted with permission). In configuration 1 (I), the slug is small enough to be fully accommodated within the cap and bursts at the cap surface. In configuration 2 (II), the bubble nose bursts from the cap into the air above while its tail is still in the lower liquid. In configuration 3 (III), bubble expansion during rise causes the lower viscosity liquid to intrude through the upper more viscous liquid, such that bubble burst occurs in the lowviscosity liquid that is emplaced above the cap. 
High magma crystallinity will not only increase viscosity but also create a non-Newtonian rheology.

Rheometry of synthetic and analogue magmas demonstrates that high crystallinities (> $20-40$ vol\% in basalts) produce both yield strengths and shear-thinning behavior (e.g. Hoover et al., 2001; Jerram et al., 2003; Caricchi et al., 2007; Mueller et al., 2010; Picard et al., 2013; Moitra and Gonnermann, 2015). Consequently, the slug model has been modified to include both shear-thinning rheology and an increasing viscosity towards the surface, which affect bubble overpressures at burst (Von der Lieth and Hort, 2016). In contrast, Suckale et al. (2016) depart from the slug model, suggesting that Strombolian eruptions occur by tensile failure of a porous, rigid plug, generated by bubble overpressure below the plug and aided by regional tectonic stress.

Solid particles also directly affect bubbles by trapping, deforming, and/or splitting them (Belien et al., 2010; Tran et al., 2015; Oppenheimer et al., 2015; Lindoo et al., 2017; Barth et al., 2019). Migration regimes of growing bubbles depend primarily on particle concentrations (Oppenheimer et al., 2015). At low particle fractions, the liquid-particle suspension is approximately Newtonian and growing bubbles are round. At random loose packing (RLP, "the loosest possible random packing that is mechanically stable"; Onoda and Liniger, 1990), the bubbles deform as they grow. At random close packing ( $\mathrm{RCP}$, the maximum random packing), gas propagates in a fracture-like pattern. Therefore, interaction with solids in a crystal-rich upper magma must also affect bubble morphology and rise dynamics during Strombolian eruptions. In this context, we will refer to Taylor bubbles in

91 Newtonian liquids as "slugs" but use the term "bubble" for all geometries of bubbles in non-

92 Newtonian suspensions.

Here, we use analogue experiments to model gas bubbles rising below and into a particle-laden layer, investigating how particles in suspension affect the slug rise model for Strombolian eruptions. We show that particle-rich suspensions affect bubble morphology and bubble rise and generate burst dynamics consistent with observations at Stromboli Volcano, Italy. Our data suggest a weak 
plug model as a source mechanism for Strombolian eruptions at hydrous open-system mafic volcanoes.

\section{Activity at Stromboli Volcano, Italy}

100 Stromboli Volcano is persistently active with eruption recurrence times of $10-10^{3}$ seconds (e.g. 101 Barberi et al., 1993; Rosi et al., 2013). Eruptions during "normal activity" last up to tens of seconds 102 and include several pulses with durations of 0.05 - 2 seconds (Patrick et al., 2007; Taddeucci et al., 103 2013; Gaudin et al., 2014). The frequency and intensity of normal activity at Stromboli varies with time, sometimes within days (Harris and Ripepe, 2007a). Strombolian eruptions are classified into four sub-categories: type 0 emit very few small particles at high velocity; type 1 eject mainly coarse ballistics; type 2 generate ash-rich plumes with (2a) or without (2b) ballistics (Patrick et al., 2007; Harris et al., 2013; Leduc et al., 2015). Eruptions derive from the North-East (NE), central, and SouthWest (SW) vents, with shorter, louder explosions in the NE (typically type 1), and longer, pulsatory events in the SW (typically type 2; Ripepe and Marchetti, 2002; Chouet et al., 2003; Harris and

110 Ripepe, 2007a).

111 These eruptions produce pyroclasts with an average of $45-55$ vol\% phenocrysts during normal 112 activity (Landi et al., 2004; Metrich et al., 2010). Plagioclase begins to crystallize at $2-4 \mathrm{~km}$ depth 113 (Métrich et al., 2010), but plagioclase crystallinity rapidly increases $~ 800 \mathrm{~m}$ below the crater (Landi 114 et al., 2004; Agostini et al., 2013). Crystal-poor basalt resides at depths $>7 \mathrm{~km}$ and only erupts during paroxysms (Metrich et al., 2010; LaFelice and Landi, 2011). This volatile-rich lower magma provides the gas source for normal Strombolian eruptions. Therefore, a rheological transition from a crystal-poor basalt to a crystal-rich cap begins at $2-4 \mathrm{~km}$ depth and accelerates at $\sim 0.8 \mathrm{~km}$ depth.

118 These depths correspond to estimated slug source depths of 0.8 and $2.7 \mathrm{~km}$ (Burton et al., 2007),

119 estimates which assume, however, that bubbles form at chemical equilibrium and ascend quickly 120 without substantial exchange of volatiles with the melt. 
121 Estimates of gas flux, however, show that Strombolian eruptions account for less than $10 \%$ of the

122 total mass of gas erupted; most outgassing occurs via puffing or quiescent degassing (Francis et al., 123 1993; Allard et al., 1994; Harris and Ripepe, 2007b). Gas compositions indicate that non-explosive 124 outgassing has a shallow source (Burton et al., 2007). Pyroclasts ejected during puffing are less crystalline than in normal explosions (Landi et al., 2011). Puffing generates lower amplitude acoustic signals than Strombolian eruptions, and is generally active in one vent at a time, but migrates between vents, and is therefore interpreted as a train of small weakly overpressured bubbles of shallower origin than those that generate Strombolian eruptions (Ripepe et al., 2007; Landi et al., 2011; Lane et al., 2013).

\section{Methods}

\subsection{Experimental set-up}

132 We performed experiments using the same apparatus as Del Bello et al. (2015) and Capponi et al.

133 (2016), although with a modified bubble injection system (Figure 2), and same low-viscosity liquid as

134 Capponi et al. (2016). A vertical 3-m-high tube of internal diameter $D=0.0257 \pm 0.0001 \mathrm{~m}$ was

135 connected to a bubble trap at its base and to a vacuum pump at the top to reduce ambient pressure

$136\left(\mathrm{P}_{\text {surf }}=0.3 \pm 0.1 \mathrm{kPa}, 1 \pm 0.2 \mathrm{kPa}, 50 \pm 1 \mathrm{kPa}\right.$, and $\left.101 \pm 1 \mathrm{kPa}\right)$ and scale for near-surface gas

137 expansion at Stromboli (James et al., 2008; Lane et al., 2013). The tube was filled to $1.43 \pm 0.01 \mathrm{~m}$

138 above the bubble trap with silicone oil (Wacker Chemie AG - AS 100; viscosity $0.1 \pm 0.05$ Pa s; surface tension $0.021 \mathrm{~N} / \mathrm{m}$ ) and polypropylene particles (A. Schulman - Icorene N4420-1200, sieved

140 by hand). Microscope analysis of 200 particles revealed angular morphologies with an average

141 equivalent sphere diameter of $0.8 \mathrm{~mm}$ (standard deviation of $0.48 \mathrm{~mm}$; Supplementary Material).

142 The particle density $\left(900 \mathrm{~kg} / \mathrm{m}^{3}\right)$ was slightly lower than the silicone oil $\left(990 \mathrm{~kg} / \mathrm{m}^{3}\right)$; therefore, the 143 particles rose to the top of the column and, at the start of each experiment, formed a layer of oil + 144 particles (the "cap") above the pure oil. The caps contained particle masses of 5.4, 14, 23, 46, and 92 


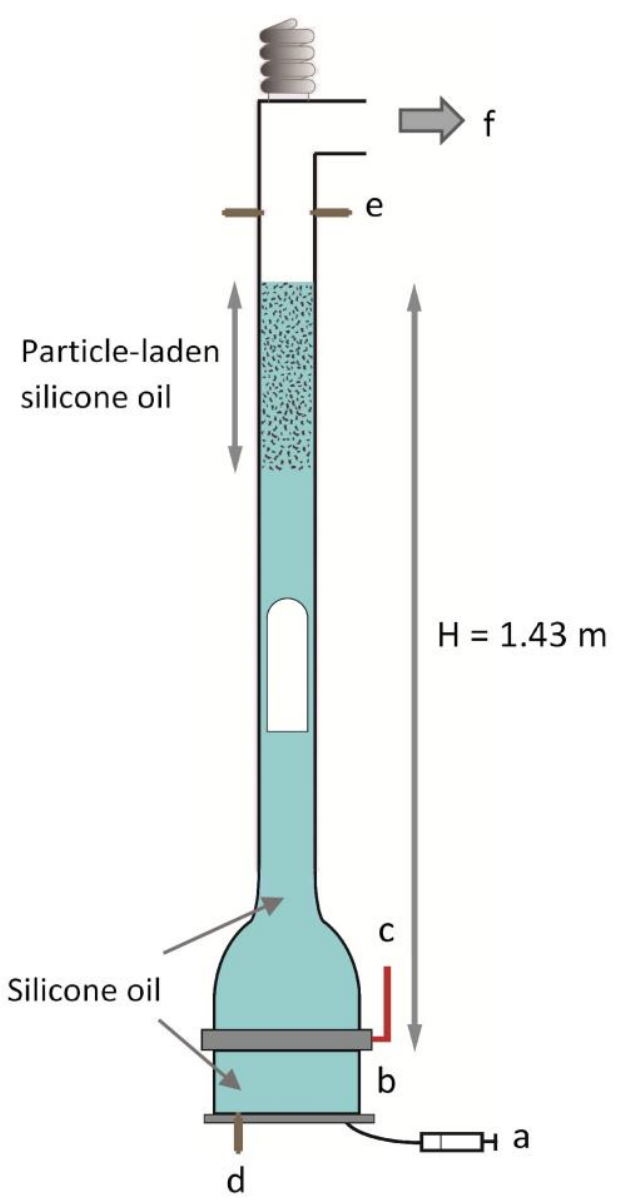

Figure 2: Experimental set-up. Gas slugs were injected through a syringe (a) into a bubble trap (b) and released using a butterfly valve (c). Measurements were made of base liquid pressure (d), gas pressure at the surface (e), along with high speed videos. Pressure at the liquid surface was controlled with a vacuum chamber (f).

147 To avoid pre-formed pathways within the cap, it was disrupted between each experiment with large

148 gas slugs that generated turbulence. This introduced small bubbles that foamed when ambient pressure was reduced to experiment pressure, and dispersed particles throughout the tube. Particle concentrations were then controlled by allowing the particles to rise until the cap reached the desired length, so that for the same mass of particles, longer caps had lower particle concentrations. For each experiment a bubble of volume $4,10,17,32$ or $49 \mathrm{ml}( \pm 10 \%)$ was injected into the bubble trap and prevented from rising by a closed butterfly valve. When released from the trap, the bubble

154 rose as a gas slug in the tube. Cap lengths were non-dimensionalized as a function of internal tube diameter (D). Particle fractions were divided by RCP to generate a normalized particle fraction, $\varphi$, for comparison with other work involving particle-rich suspensions. RCP was measured as $47 \pm 2$ vol\% by 
157 pouring dry particles in a graduated cylinder $(D=28 \mathrm{~mm})$ and tapping/shaking the container for

158 minutes until the bulk volume was constant. We estimated $\varphi$ by dividing the calculated cap length at

159 RCP by the measured cap length in each experiment. Particle fractions were overestimated when

160 particle-bearing clusters ejected during experiments remained attached to the tube walls. This error

161 was larger for shorter caps because a small loss of particles caused a larger relative change in cap

162 length. Additionally, as particle contents could vary within the cap, all reported particle fractions

163 were averages of the full cap.

164 Simply allowing the particles to rise should have created a random loose packing because of the

165 small density difference between particles and liquid (Onoda and Liniger, 1990). However, closer

166 packings occurred $(\varphi<0.92)$ because residual small bubbles shook the suspension as they ascended

167 through the particle layer during compaction. For our particles, RLP was likely near the median value

168 for packed caps ( 40 vol\% particles). RCP was not achieved in experiments.

169 Two differential pressure transducers (Honeywell 163PC01D36; sampling frequency $5 \mathrm{kHz}$ ) recorded

170 pressure changes in the air above the liquid surface with respect to the pressure in the vacuum

171 chamber (Lane et al., 2013). Two cameras recorded the experiments: a Basler acA2000-340km

172 filmed the entire column at $300 \pm 0.1 \mathrm{fps}$, and a Canon Powershot G15 recorded only the particle

\begin{tabular}{|c|c|c|c|c|c|c|c|c|}
\hline $\begin{array}{l}\text { Number } \\
\text { of exps. }\end{array}$ & $\begin{array}{l}\text { Initial bubble size } \\
(\mathrm{mL})\end{array}$ & $\begin{array}{l}\text { Surface } \\
\text { pressure }(\mathrm{kPa})\end{array}$ & $\gamma$ (plug-free) & $\begin{array}{l}\text { Mass of } \\
\text { particles (g) }\end{array}$ & $\begin{array}{l}\text { Cap length } \\
(\mathrm{cm})\end{array}$ & $\begin{array}{l}\text { Dimensionless } \\
\text { cap length (D) }\end{array}$ & $\begin{array}{l}\text { Particle } \\
\text { content (vol\%) }\end{array}$ & $\phi$ \\
\hline 9 & $4,10,17,32$ & 0.3 & $8.8-70$ & 0 & 0 & 0 & 0 & 0 \\
\hline 15 & $4,10,17,32,49$ & 1 & $0.83-10$ & 0 & 0 & 0 & 0 & 0 \\
\hline 8 & $4,10,32,49$ & 1 & $0.83-10$ & 5.4 & $3-10$ & $1.1-4.0$ & $11-39$ & $0.24-0.84$ \\
\hline 10 & $4,10,32,49$ & 50 & $(1.4-17) \times 10^{-3}$ & 5.4 & $3-6$ & $1.2-2.5$ & $18-36$ & $0.39-0.77$ \\
\hline 4 & 10,49 & 100 & $(1.6-7.8) \times 10^{-3}$ & 5.4 & $3-6$ & $1.3-2.2$ & $20-35$ & $0.43-0.75$ \\
\hline 8 & $4,10,32,49$ & 1 & $0.83-10$ & 14 & $7-12$ & $2.8-4.8$ & $24-42$ & $0.52-0.90$ \\
\hline 12 & $4,10,32,49$ & 50 & $(1.4-17) \times 10^{-3}$ & 14 & $8-14$ & $3.2-5.6$ & $21-37$ & $0.45-0.79$ \\
\hline 8 & $10,17,32,49$ & 100 & $(1.6-7.8) \times 10^{-3}$ & 14 & $7-13$ & $2.8-5.1$ & $23-42$ & $0.49-0.90$ \\
\hline 4 & 10,32 & 0.3 & $22-70$ & $22-23.5$ & $11-13$ & $4.4-5.1$ & $38-42$ & $0.82-0.90$ \\
\hline 15 & $4,10,32,49$ & 1 & $0.83-10$ & $22-23.5$ & $12-28$ & $4.6-11.0$ & $17-42$ & $0.37-0.90$ \\
\hline 10 & $4,10,32,49$ & 50 & $(1.4-17) \times 10^{-3}$ & 23 & $13-20$ & $4.9-7.9$ & $24-39$ & $0.52-0.84$ \\
\hline 12 & $2,4,10,32,49$ & 100 & $(0.32-7.8) \times 10^{-3}$ & 23 & $12-14$ & $4.5-5.4$ & $36-43$ & $0.76-0.92$ \\
\hline 4 & 17 & 1 & 3.5 & 37.2 & $20-53$ & $8.0-20.7$ & $15-39$ & $0.32-0.84$ \\
\hline 4 & $4,10,32$ & 0.3 & $8.8-70$ & 46 & 25 & $9.6-9.9$ & $39-40$ & $0.83-0.86$ \\
\hline 4 & $4,10,32,49$ & 1 & $0.83-10$ & 46 & $25-27$ & $9.6-10.5$ & $37-40$ & $0.79-0.85$ \\
\hline 1 & 32 & 0.3 & 70 & 92 & 53 & 20.7 & 38 & 0.8 \\
\hline 2 & 10,32 & 1 & $2.1-6.6$ & 92 & $52-55$ & $20.2-21.5$ & $36-38$ & $0.77-0.81$ \\
\hline 130 & $2-49$ & $0.3-100$ & $0.00032-70$ & $0-92$ & $0-55$ & $0-21.5$ & $0-43$ & $0-0.92$ \\
\hline
\end{tabular}

Table 1: Summary of experimental conditions. A more detailed list is available in Supplementary Material. 


\subsection{Suspension rheology}

We measured suspension rheology at $20^{\circ} \mathrm{C}$ using a HAAKE RheoStress 1 with a modified concentric
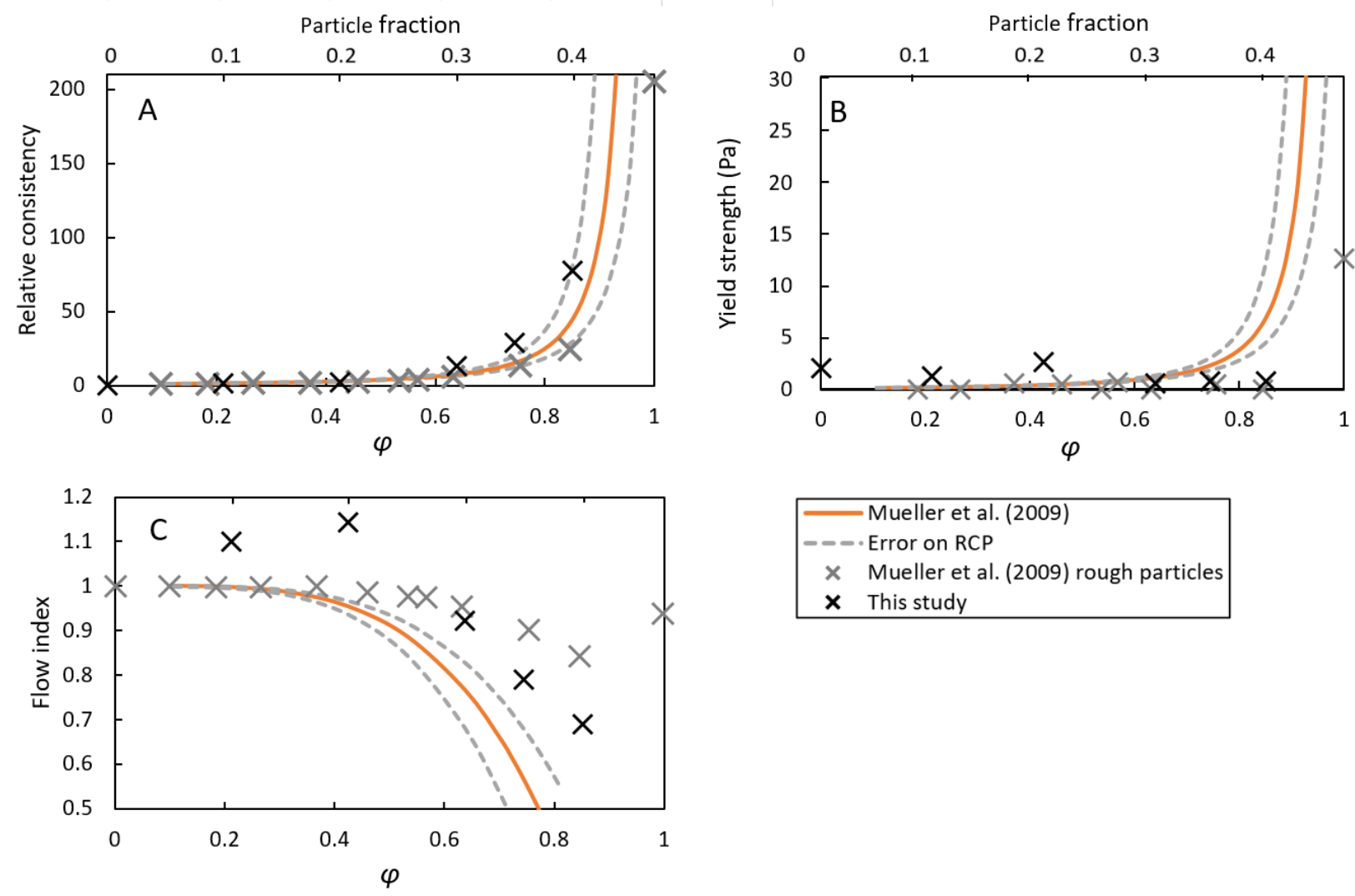

\begin{tabular}{|c|c|}
\hline \\
\hline & \\
\hline & $\begin{array}{l}\text { _Mueller et al. (2009) } \\
\times-\infty \text { Error on RCP } \\
\times \quad \text { Mueller et al. (2009) rough particles }\end{array}$ \\
\hline \multicolumn{2}{|r|}{$\mathbf{x}$ This study } \\
\hline
\end{tabular}

Figure 3: Rheology of the particle-bearing suspensions. Solid lines are calculated from the empirical model by Mueller et al. $(2009,2011)$, and dashed lines show how the error on RCP (of \pm 2 ) modify the model. Black crosses are rheology measurements with a concentric cylinder (this study), and grey crosses are measurements by Mueller (2009) for crushed particles. Together, these three datasets give an overall idea of cap rheology. A: The relative consistency is the consistency $(K)$ divided by the viscosity of the Newtonian liquid ( $0.1 \mathrm{~Pa} s$ here). $K$ has the dimensions $\mathrm{Pa} \mathrm{s}^{n}$ and is equivalent to viscosity when $n=1$. B: Yield strength. Experiment yield strengths determined through curve fitting were relatively consistent with the experimental data for crushed particles in Mueller et al. (2009). Our first experimentally measured yield strength occurred at 40 vol\% particles (Supplementary Material). C: Flow index indicates whether the suspension is shear-thinning $(n<1)$, shearthickening $(n>1)$, or Newtonian $(n=1)$. Here, our data falls between the crushed particles and model in Mueller et al. (2009), possibly indicating large errors. The apparent shear-thickening in experiments with low $\varphi$ may also have been caused by particle rise. 

errors on viscosity are $\pm 0.02 \mathrm{~Pa} \mathrm{~s}$, although greater errors were caused by bubbles in suspension and particle rise. We fitted our measurements to a Herschel-Bulkley (1926) model:

$$
\tau=\tau_{y}+K \dot{\gamma}^{n}
$$

184 where $\tau$ is applied stress, $\tau_{y}$ is yield strength, $n$ is flow index, and $K$ is consistency.

185 Due to the possibility of large experimental errors, we compared our data to models by Mueller et 186 al. $(2009,2011)$ by determining $K_{r}$ (relative consistency), $\tau_{y}$, and $n$ using equations $2.4,4.1$, and 5.2 187 from Mueller et al. (2009), which requires a fitting parameter, $\varphi_{m}$, that represents the particle 188 fraction at which suspensions can no longer be sheared. We use our measured RCP as a best approximation of $\varphi_{m}$. Indeed, although sheared suspensions typically generate $\varphi_{m}>\mathrm{RCP}$, Mueller et al. (2009) generate values close to RCP. The aspect ratio used to determine $n$ was also generated 191 from RCP, using equation 4 in Mueller et al. (2011). Additional details are available in Supplementary 192 Material.

\subsection{Scaling considerations}

194 We modelled our experiments assuming that rapid (non-equilibrium) bubble expansion near the 195 surface at the volcano scale can be approximated at laboratory scale by varying surface pressure

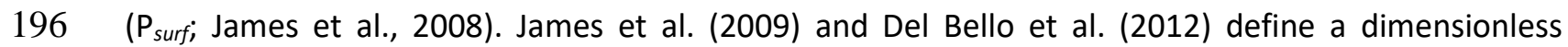
expansion index $(\gamma)$ for slug flow in a Newtonian liquid as

$198 \quad \gamma=\frac{\rho_{l} g A^{\prime} V_{a}}{P_{\text {surf }} \pi r^{2}\left(1-A^{\prime}\right)}$,

199 with $\rho_{\text {/ }}$ the liquid density, $g$ the gravitational acceleration, $A^{\prime}$ the dimensionless cross-sectional area 200 of the falling liquid film (equation (28) in Del Bello et al., 2012), $V_{a}$ the slug volume at $P_{\text {surf }}$ if it were at 201 equilibrium, and $r$ the tube radius. Rapid bubble expansion occurs when $\gamma>1$. Therefore, $\gamma$ provides 202 an estimate of bubble expansion conditions in the Newtonian liquid below the cap, but ignores the 
203 viscous resistance from the cap. Our range of $P_{\text {surf }}$ covers the full range of slow (equilibrium) and

204 rapid (non-equilibrium) bubble expansion.

205 The density and viscosity of the lower liquid allowed bubble rise parameters, such as falling film 206 thickness, to be scaled to bubble rise in the lower (basaltic and crystal-free) magma at Stromboli 207 (Supplementary Table 1; Capponi et al., 2016). To account for uncertainty on cap thickness and 208 crystallinity at Stromboli, we covered a range of thicknesses and particle contents in experiments.

209 We did not attempt to scale particle sizes to crystal sizes at Stromboli. Instead, particle sizes were 210 chosen to avoid wall effects and preserve flow properties. We chose a conservative particle size that

211 fit $>30$ particles in the inner tube diameter to allow for the counter-flow of liquid + particles during 212 bubble rise in the suspension to approach a 10-particle thickness. Smaller particles could have 213 introduced non-negligible capillary and cohesion forces and increased the particle rise (cap "reset") 214 time between experiments.

215 Other simplifications included: smooth, cylindrical walls, no density-driven convection, no bubbles in 216 the solids-rich cap, little variation in particle shape/size, a single liquid phase, no diffusion between 217 phases, and an abrupt change from a particle-absent to particle-rich suspension. We therefore 218 ignored the effects of near-surface crystallization, vesiculation, and outgassing on magma 219 convection (Palma et al., 2011; Beckett et al., 2014; Gurioli et al., 2014) and melt viscosity, and did 220 not account for the decrease in overpressure from non-adiabatic bubble expansion (Bagdassarov, 221 1994). Furthermore, we neglected the effect of crystal-scale bubbles and variations in crystal shape 222 and size on cap rheology. Additional details are available in Supplementary Material.

\section{Results}

224 After injection, gas slugs rose through the column of silicone oil until they reached the layer of oil + 225 particles (the cap). Subsequent gas migration behaviors depended on both the particle fraction in 226 the cap and the ratio of bubble size to cap length. 
In a tube filled with a Newtonian liquid, the slug base rises at a constant velocity, while the slug nose accelerates until it bursts at the surface (e.g. Seyfried and Freundt, 2000; James et al., 2008, 2013; Lane et al., 2013; Del Bello et al., 2015). In our experiments, the rise velocity of the slug base in the Newtonian liquid below the particle-bearing cap was constant, regardless of cap parameters and surface pressure. On average, slug base velocity $U_{\mathrm{s}}=0.149 \mathrm{~m} / \mathrm{s}$ (standard deviation $0.005 \mathrm{~m} / \mathrm{s}$ ). This velocity is within error of the calculated velocity of $0.157 \pm 0.009 \mathrm{~m} / \mathrm{s}$ following Wallis (1969; Supplementary Material).

\subsection{Geometrical flow configurations}

Slug flow in a liquid overlain by a higher viscosity liquid can be categorized by flow configurations
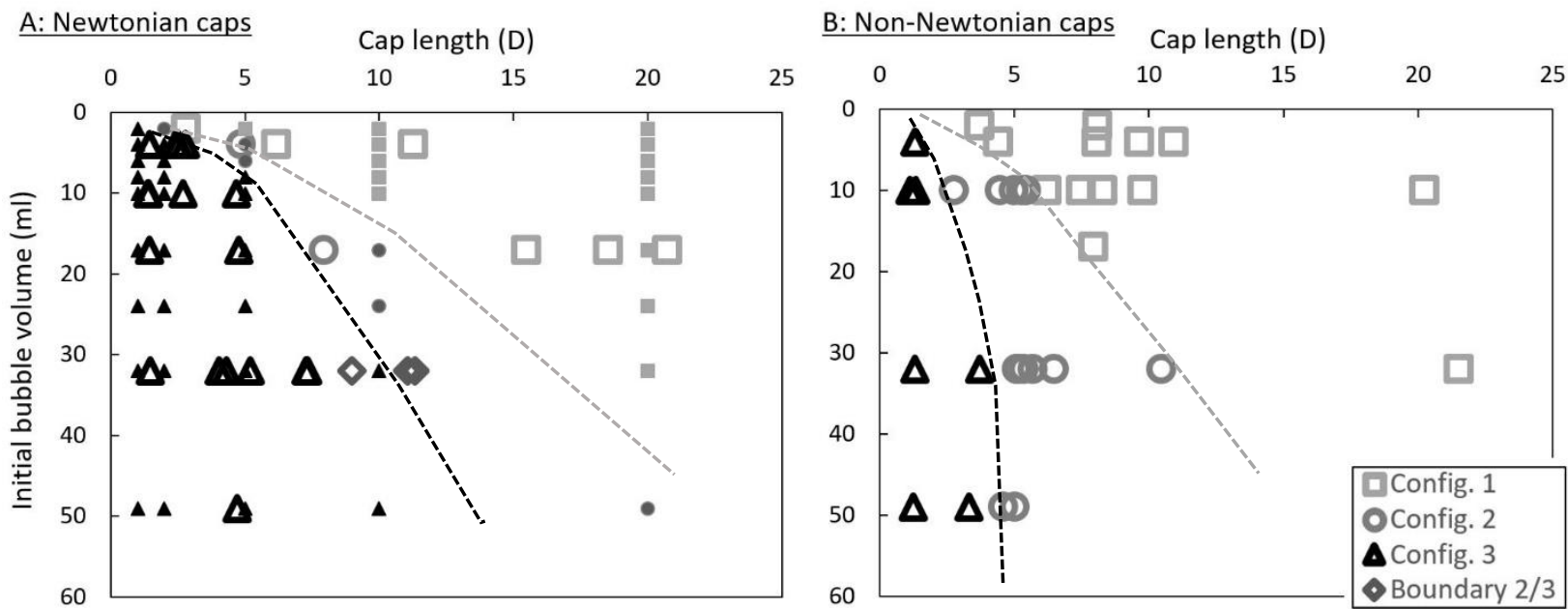

Figure 4: A: Flow configurations in Capponi et al. (2016; smaller filled symbols) and in experiments with Newtonian caps in this study (< 30 vol\% particles; large empty symbols). The "boundary 2/3" category describes experiments that were difficult to categorize due to the opacity of the particle layer: the lower liquid may or may not have reached the surface shortly ahead of the bubble. B: Flow configurations in experiments with non-Newtonian caps (> 30 vol\% particles). Since all experiments with > 30 vol\% particles are shown here, viscosities vary over 1 order of magnitude. The dashed lines guide the eye to the transitions between regimes. All experiments in this figure have surface pressure $=1 \mathrm{kPa}$. 
242 Our rheology measurements suggested that caps with $<30$ vol\% particles behaved as a Newtonian

243 fluid ( $\mathrm{n} \approx 1$; Fig. 3) with effective viscosities between 0.1 Pa s (particle-free) and 0.8 Pa s (30 vol\% 244 particles), which approached those used by Capponi et al. (2016; 1 Pa s). The presence of particles in 245 these experiments did not significantly affect flow configurations (Figure 4A).

246 At particle contents $>30$ vol\%, the cap rheology was non-Newtonian ( $\mathrm{n}<1$ with a low yield strength,

247 Figure 3). Under these conditions, transitions between configurations occurred at shorter cap 248 lengths (Figure 4B) compared to experiments with particle-poor caps, consistent with the effect of a 249 greater cap viscosity (Capponi et al., 2016). The experiments shown in Figure 4B contained $30-43$ 250 vol\% particles, corresponding to a variation in consistency of slightly over one order of magnitude 251 (Figure 3).

\subsection{Rheological flow regimes}

Bubble morphology and rise dynamics in the cap depended on cap rheology. Flow regimes were determined through visual characteristics of bubble rise (Figures 5 and 6). In some cases, gradients in particle fraction caused "hybrid" regimes, such that bubbles behaved differently at the bottom and top of the cap.

When the cap comprised a dilute particle suspension, bubble expansion in the lower liquid caused the particle-free oil to intrude into the center of the cap ahead of the bubble (Figure 7A). In the cap, the bubble remained axisymmetric but its diameter decreased and it developed a rounded base. This sequence matches observations of slug flow into a Newtonian liquid of higher viscosity (Del Bello et al., 2015; Capponi et al., 2016), and thus we classify this regime as a slug flow regime (Figure 5A). At low $\mathrm{P}_{\text {surf, }}$ the film at the bubble nose broke in several places and discharged a few liquid-particle fragments, in contrast to the particle-free scenario, where bubble burst generated one accelerated 264 droplet.

265 The side flow regime occurred with higher particle fractions. Here, bubble expansion in the lower 266 liquid caused a finger of liquid to intrude the side of the cap and, although the lower portion of the 
cap was diluted by the intruded liquid, most of the cap rose upwards. When it reached the cap, the

268 bubble nose filled the finger and then slowed as it pushed the cap upwards, while the tail of the bubble continued rising as liquid drained from the falling film at the bubble walls. The bubble thus became shorter and wider, and slowly migrated upwards. The duration of coupled rise of the bubble and cap was greater for smaller bubbles and for longer caps with higher particle concentrations. In the cap, the bubble flowed against the tube wall, usually as a linear continuation of the original finger although in some cases it also spiraled slightly (Figure 5B \& 7B). The particle suspension remained in one piece, deforming around the bubble. Bubble burst occurred at the side of the tube and was often accompanied by ejection of clasts that fountained above the suspension surface.

A

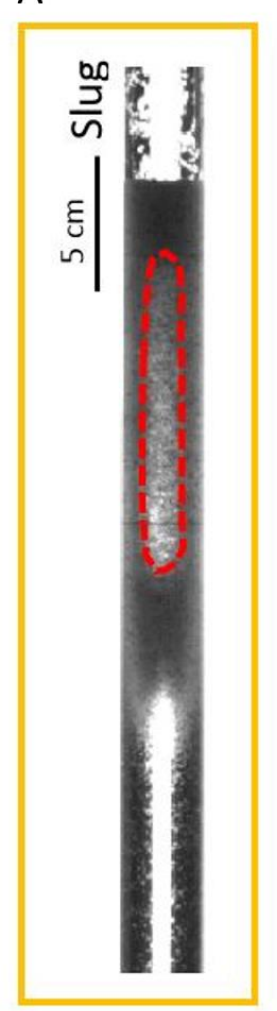

B

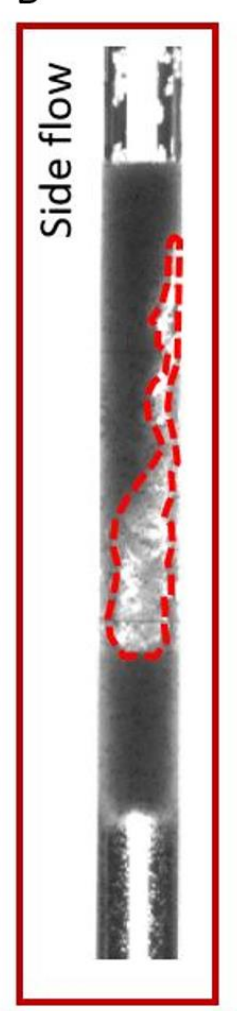

C

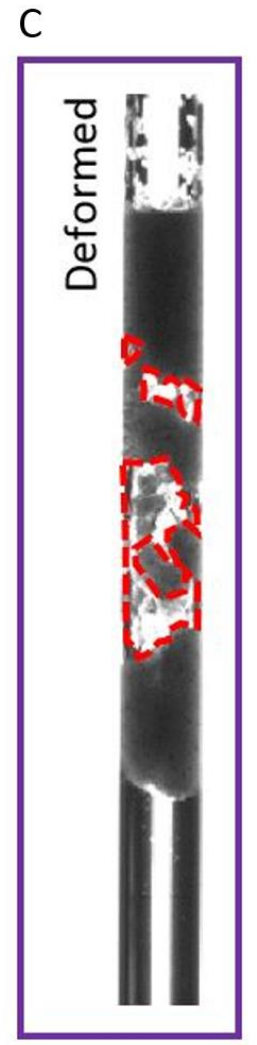

D

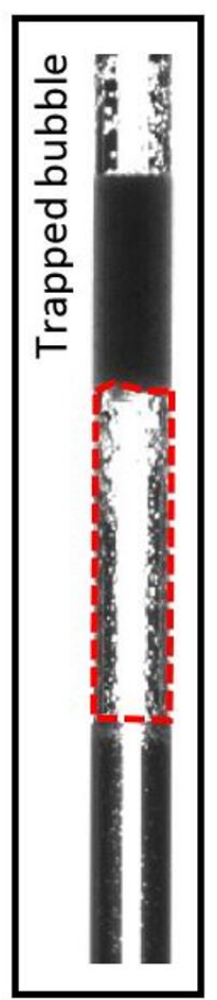

Figure 5: Comparison of the different regimes discussed in this research. These illustrative examples were produced by different experimental conditions.

276 A further increase in particle fraction induced a transition to the deformed regime. Here, bubble expansion in the lower liquid caused the cap to slide upwards as a plug, presumably with a film of oil at the wall; we did not explore whether the dynamics would be significantly different with a rough wall. Again, the bubble paused before entering the cap; the duration of this pause increased with particle fraction. In the cap, the bubble advanced intermittently, the particle suspension often 
At high particle fractions and low bubble expansion, some bubbles remained trapped indefinitely
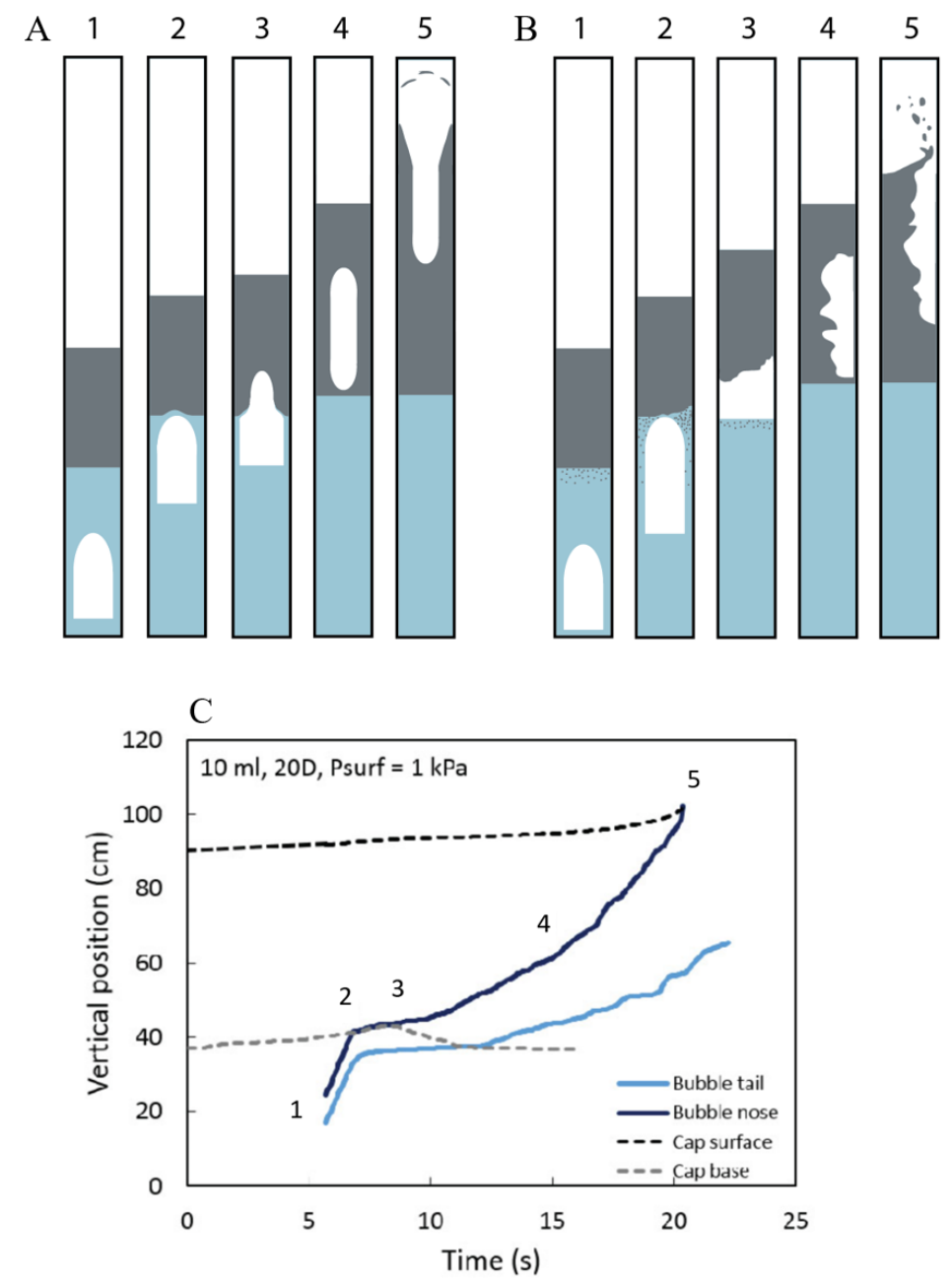

Figure 7: Bubble rise in the rheologically layered experiments can be subdivided into stages of ascent, as shown in (A) for a Newtonian cap and (B) for a non-Newtonian cap. (C) Shows tracks of the bubble, the cap, and the surface of an experiment in the deformed regime, for a bubble of initial volume $10 \mathrm{ml}$ and $\gamma>1$. First, the slug rose in the lower liquid (1). When the slug reached the cap (2), bubble behavior depended on flow regime. In the slug flow regime, bubbles flowed seamlessly from the lower liquid into the upper liquid. In the side and deformed regimes, bubbles were temporarily trapped below the cap. As the bubble pierced the cap (3), a portion of the liquid + particle suspension flowed down the side of the tube, forming a thick bubble film that is viscously supported by the tube wall. In stage (4), the bubble was fully encased in the cap, and in (5) the bubble burst at the surface. Note that in stage (4) the shear-thinning rheology is visible in the overall curvature of the bubble base position in (C). Base velocities of conduit-filling bubbles are constant in Newtonian liquids (White and Beardmore, 1962; Viana et al., 2003). Here, the bubble base accelerates upward with time as its increasing overpressure interacts with the shear-thinning cap. 
294 Of the four parameters varied in our experiments (particle fraction, initial bubble volume, surface 295 pressure, and cap length), particle fraction provided the dominant control on regime transitions. 296 Bubble expansion, controlled mainly by surface pressure but also by initial bubble size, had a 297 moderate effect. Cap length, while affecting other flow characteristics, did not affect regimes (Figure 298 6).

299 Slug flow occurred only at particle fractions $<30$ vol\%, or $\varphi<0.64$, regardless of other parameters 300 (Figure 6, orange dashed line). The departure from the slug flow regime at $\varphi \approx 0.64$ corresponds 301 approximately to the departure from Newtonian rheology (Figure 3C). Immediately above $\varphi \approx 0.64$, bubbles travelled through the cap in either the side flow or deformed regime. The transition between these regimes depended on both the expansion index $y$ (an indicator of stress on the cap) and particle fraction. In experiments with $\gamma<1$ (low bubble expansion), the deformed bubble regime was observed in experiments with particle contents $>35$ vol\% $(\varphi>0.75)$. At $\gamma>1$, the deformed regime began at $\sim 37$ vol\% particles $(\varphi \approx 0.80$; Figure $6 \mathrm{~A})$.

307 Bubbles were trapped at $y<1$ and high particle volume fractions. Notably, all bubbles with $y<1$ that 308 interacted with a cap containing $>37$ vol\% particles $(\varphi>0.80)$ were trapped, even for thin caps 309 (Figure 6A,B). Bubble entrapment below, rather than within, the cap (Figure 5D) also occurred 310 primarily at $\varphi>0.80$, although bubble entrapment within the cap occurred at $\varphi>0.7$, plausibly 311 recording a hybrid regime between trapped bubbles and bubbles that break the surface. All trapped 312 bubbles applied buoyancy forces $<0.6 \mathrm{~N}$ on the cap (Figure 6C). 
A
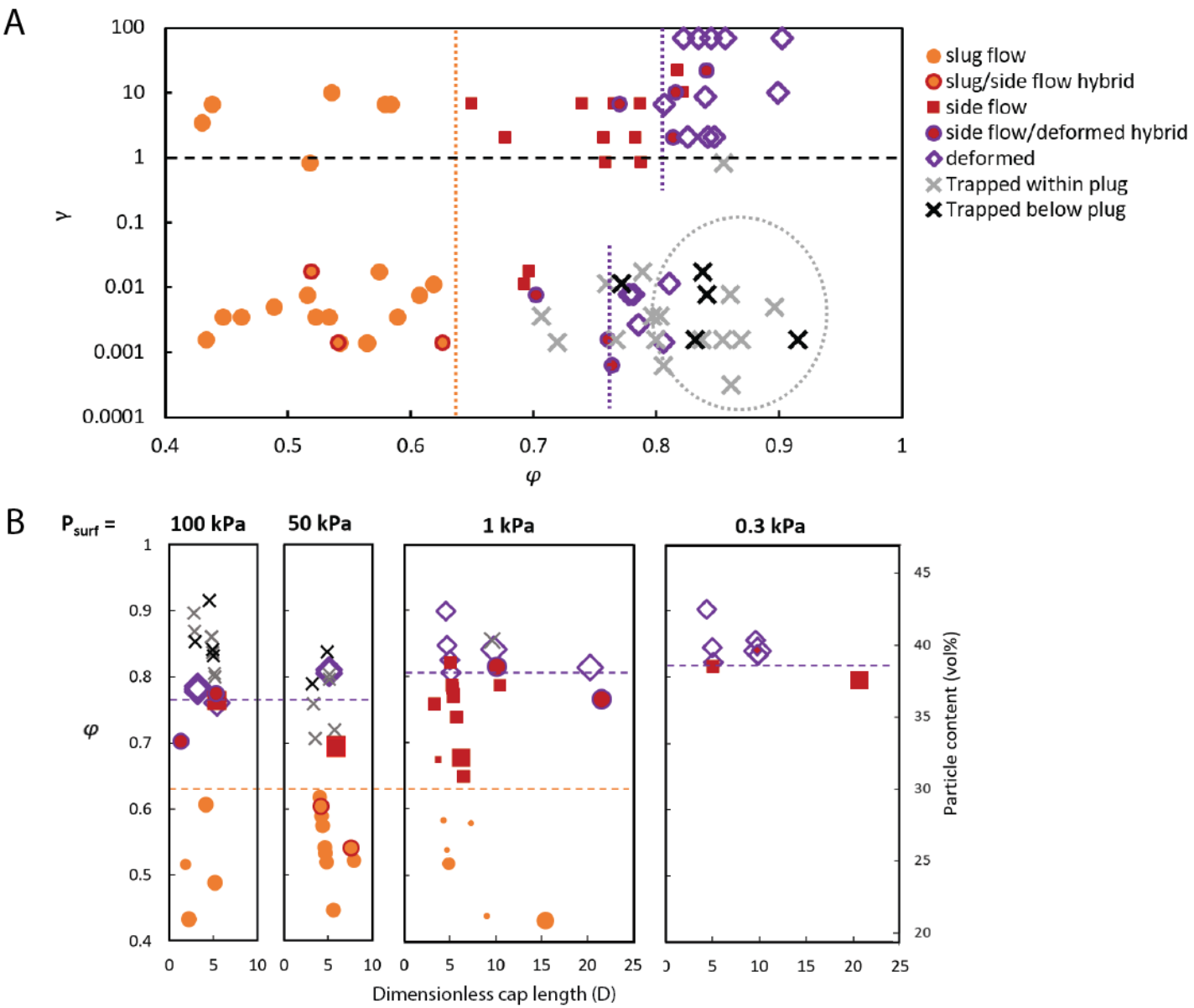

C

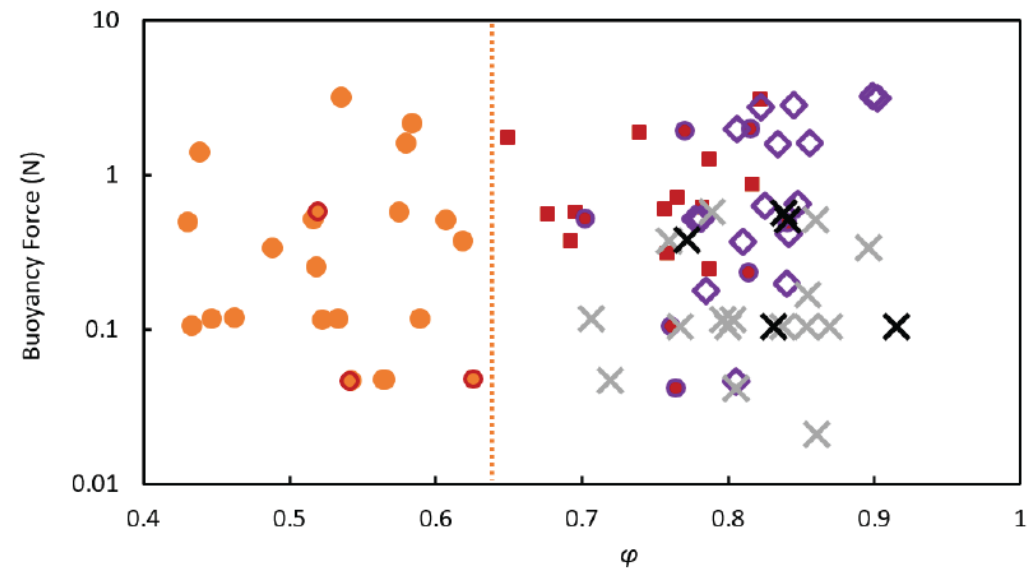

Figure 6: Diagrams of rheological regimes. (A) The dimensionless expansion index $\gamma$ (James et al., 2009; Del Bello et al., 2012), indicates whether the bubbles could theoretically expand to equilibrium pressure $(\gamma<1)$ or not $(\gamma>1)$ in the absence of a cap. $\gamma$ gives an indication of stress on the cap from bubble overpressure and expansion for given initial bubble volumes and surface pressures. Dotted lines represent approximate regime transitions, while the dotted grey circle represents an overall area occupied by the trapped regimes. (B) Deconstruction of the effect of cap length and surface pressure on regime transitions. Each box contains experiments at a different surface pressure. Cap length does not affect regime transitions, but surface pressure does have a minor role. Symbols and dotted lines as in (A), with symbol size indicating configurations: large symbols are configuration 1; medium symbols are configuration 2; smallest are configuration 3 and were only observed at $P_{\text {surf }}=1 \mathrm{kPa}$ due to experimental conditions. (C) Bubble buoyancy force applied on the cap when the bubble reaches the bottom of the cap. (Therefore, values depend on both bubble size and cap length.) 
315 The particle-rich caps also affected surface level rise, bubble burst dynamics, and acoustic signals emitted during burst. Figure 8 compares maximum surface height variations in experiments containing the same mass of particles (with varying cap lengths) for experiment suites with a given bubble size. An increasing surface height indicates bubble expansion. In the particle-free scenario, rapid bubble expansion accelerated the liquid ahead of the bubble, so that surface height increased substantially. At $\varphi<0.64$ (Newtonian cap), the total surface rise was only slightly reduced, as exemplified by experiments with $17 \mathrm{ml}$ bubbles. Maximum heights in experiments in the side flow and deformed regimes were significantly reduced (by about half) compared to the particle-free scenarios, indicating that the gas was more compressed when it reached the surface.

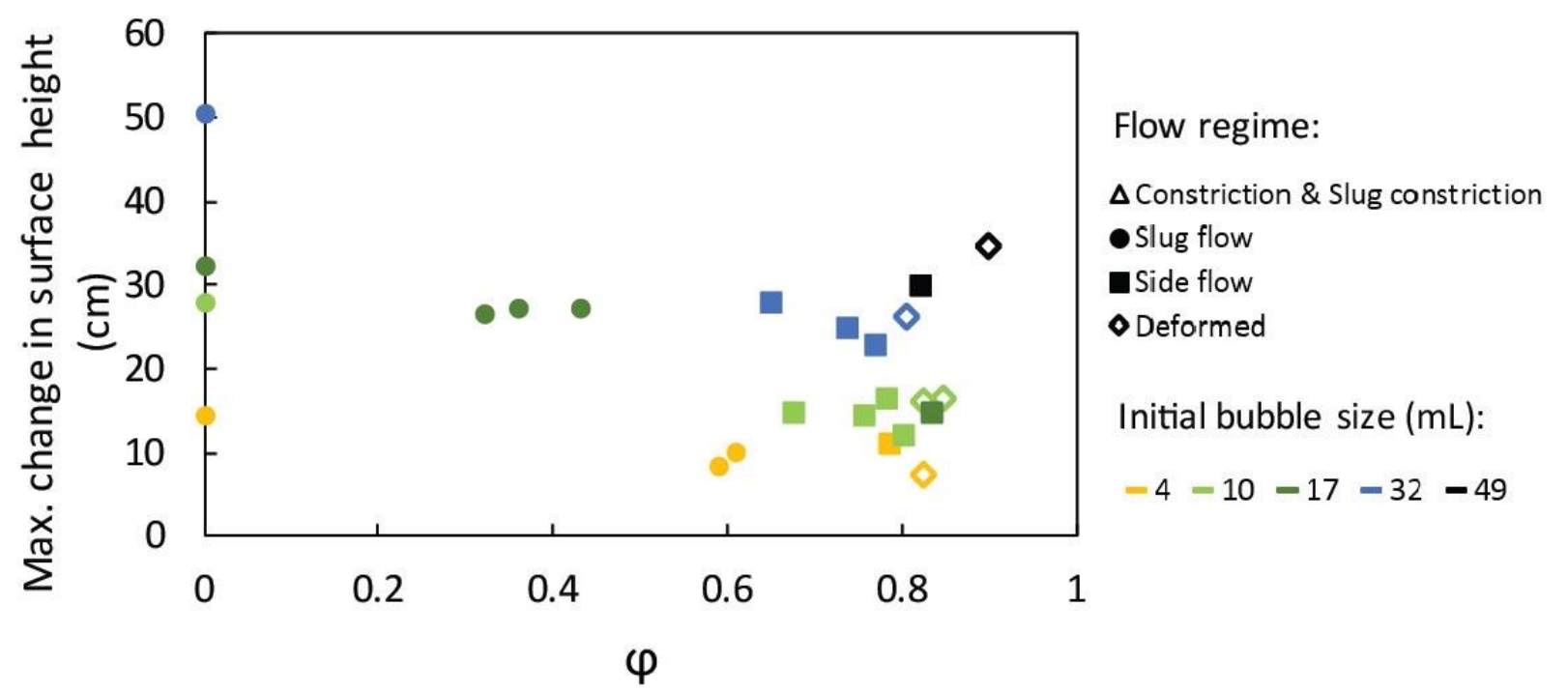

Figure 8: Total surface rise for experiments containing $23 \mathrm{~g}$ particles (and $37 \mathrm{~g}$ for the $17 \mathrm{~mL}$ bubble series) and at $P_{\text {surf }}=1 \mathrm{kPa}$. A surface height of 0 indicates the position at t 0 , which is $1.43 \mathrm{~m}$ above the bubble trap. Since particle mass is constant within each series, an increase in particle fraction causes a decrease in cap length. Colors indicate initial bubble size, and shapes indicate flow regime.

324 Figure 9 shows examples of acoustic signals for bubble burst in a particle-free (single viscosity) 325 experiment and in two experiments with particle-rich caps. In the side flow and deformed regimes, 326 the acoustic signals were more complex and smaller in amplitude than in the slug flow regime. The 327 decrease in amplitude was complemented by longer signal duration, and thus an increase in the 328 time during which expanding gas was emitted from the ruptured surface. Experiments within the 
deformed regime that had bigger bubbles and longer caps were more likely to generate several acoustic pulses, further increasing the total signal duration. This pulsatory style was occasionally captured in the camera images as impulsive variations in clast ejection velocities.

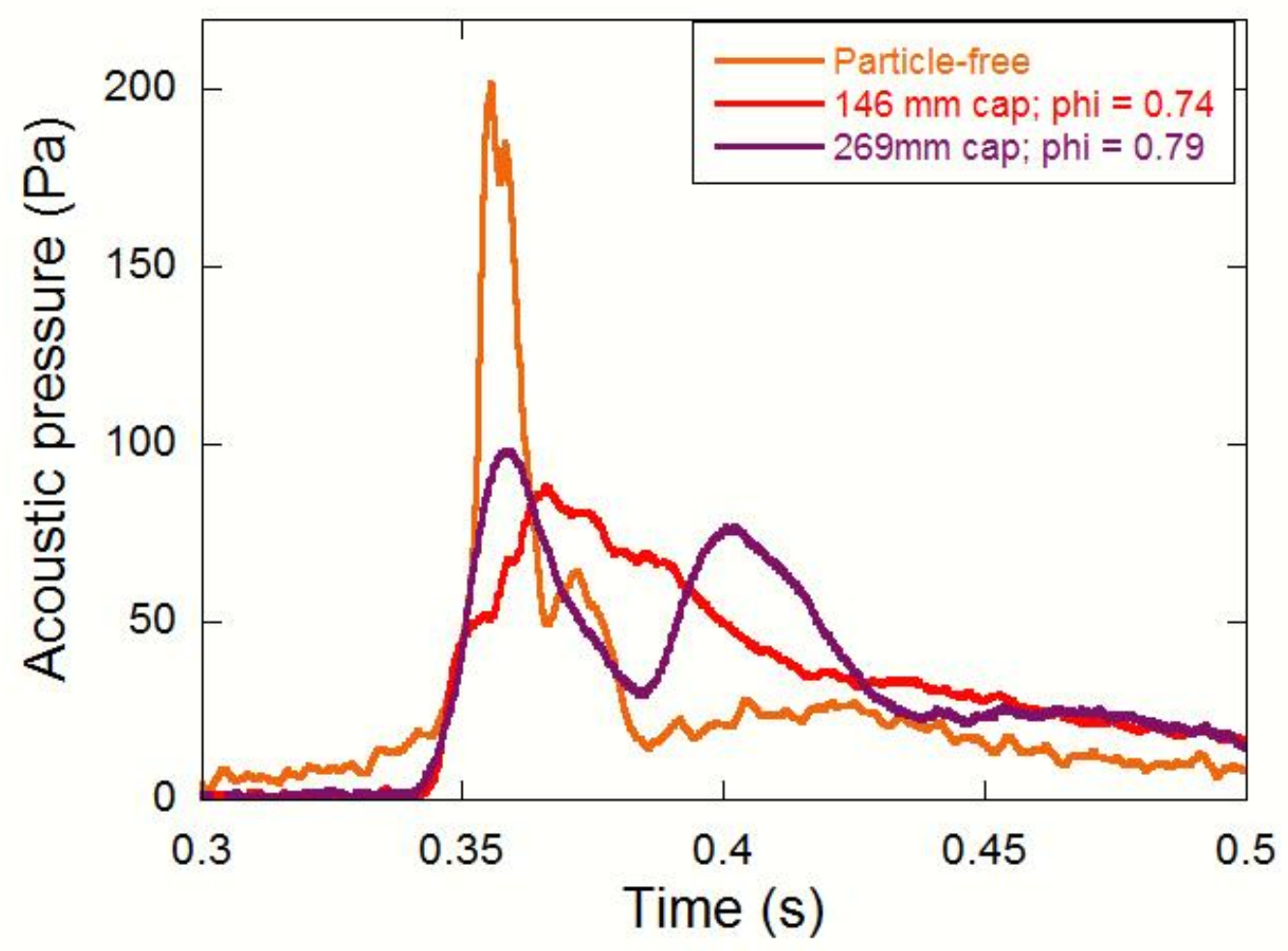

Figure 9: Example acoustic signals for bubbles of initial volume $32 \mathrm{~mL}$, and at surface pressures of $1 \mathrm{kPa}$. The signal generated by a particle-free experiment (orange) is significantly louder and shorter than the particle-rich examples, which are in the side flow regime (red), and a side/deformed hybrid regime (purple).

\section{Discussion}

\subsection{Flow configurations: comparison with Newtonian experiments}

334 Flow configurations (Fig. 1) are a geometrical consequence of varying bubble and cap sizes; in

(Del Bello et al., 2015; Capponi et al., 2017). In our experiments with sufficiently low particle 
339 al. (2016) only in the style of slug burst in configurations 1 and 2, where the particle-bearing film

340 above the slug nose broke in several places; the result was emission of several particle-liquid clots

341 rather than one accelerated drop. This multi-source rupture was likely caused by particle-generated

342 discontinuities in the rapidly thinning film. For non-Newtonian caps $(\varphi>0.64)$, our experiments

343 showed that transitions in flow configurations shifted toward shorter caps, consistent with the

344 effects of increased viscosity (Capponi et al., 2016). These observations suggest that flow

345 configurations can be estimated using simplified rheological descriptions of the cap, regardless of

346 bubble behavior within that cap.

$347 \quad$ 5.2. Rheological flow regimes

348 Particle fraction in the cap exerted a major control on regime transitions between slug flow, side 349 flow, deformed bubbles, and trapped bubbles, consistent with Oppenheimer et al. (2015). We compare these transitions to the effects of particles on cap rheology (Figure 3).

351 The first regime transition, from slug flow to side flow, occurred at $\sim 30$ vol\% particles $(\varphi \approx 0.64$; Fig.

352 6). At this value, shear-thinning and consistency increased dramatically, indicating the onset of non-

353 Newtonian rheology and weak interactions between particles. The occurrence of particle clusters

354 with a weak yield strength may have contributed to the irregular shape of the bubble as it rose

355 through a heterogeneous cap. Inefficient packing near the tube walls, where particle concentrations

356 and suspension consistency were lower than in the middle of the tube, may have aided bubble rise,

357 while a small yield strength may have suppressed thin falling films, such that a larger physical 358 dimension was required for the exchange down-flow to overcome yield strength.

359 The next regime transition, from side flow to deformed bubbles, depended weakly upon stress on 360 the cap (generated through bubble expansion, overpressure, and buoyancy; Fig. 6 ). $\nu$ is an imperfect 361 measure of bubble expansion regimes since it ignores the cap, but it approximates stress on the cap 362 from bubble expansion and overpressure. At low stress $(\gamma<1)$, the transition occurred at $\varphi \approx 0.75$. At 363 higher stress $(\gamma>1)$ the transition occurred at $\varphi \approx 0.80$, a value that corresponds with a significant 
364 increase in yield strength in particle-bearing suspensions (e.g. Mueller et al., 2009; Brown et al., 365 2011; Moitra and Gonnermann, 2015). Yield strength is generally associated with pervasive networks 366 of interacting particles (Caricchi et al., 2007; Mueller et al., 2009; Picard et al., 2013).

367 The transition to deformed bubbles at $\varphi \approx 0.75-0.80$ occurs at slightly lower $\varphi$ than the random 368 loose packing (RLP) for spheres at $\varphi=0.86$ (Jerkins et al., 2008). RLP is also associated with pervasive 369 particle networks (Onoda and Liniger, 1990) and deformed bubbles (Oppenheimer et al., 2015). Our 370 experiments show an added constraint of applied stress, however, with the regime transition 371 increasing from $\varphi \approx 0.75$ to 0.80 with increased $\psi$. The high bubble overpressure $(\leq 100 \mathrm{kPa})$ in

372 Oppenheimer et al. (2015) further suggests that RLP may provide the upper bound for transition to 373 deformed bubbles at high stress. Since bubble deformation is controlled primarily by networks of 374 interacting particles, this stress-dependence may suggest that particle networks begin at moderate $375 \varphi(\approx 0.75)$ before becoming pervasive at $\varphi \approx 0.86$. However, other factors may affect regime transitions, such as variable particle shape and size, whether the suspension is static or pre-sheared, and experimental uncertainties.

\subsection{Bubble trapping mechanism}

Bubble rise through the cap requires shearing of the liquid-particle mixture because surface tension

380 prevents bubble rise in the liquid network between particles. As surface tension is negligible on the

381 tube (slug) scale (Bo >> 1), the indefinite trapping of bubbles in or below the cap indicates that

382 buoyancy was insufficient to overcome the strength of the cap in those experiments. Figure $6 \mathrm{C}$ 383 shows that buoyancy force and cap rheology $(\varphi)$ alone do not determine whether a bubble is trapped, and that stresses from bubble overpressure and bubble nose acceleration (reflected in $\gamma$; Fig. 6A) are also important. Trapped bubbles occurred exclusively for $\gamma<1$ and $\varphi>0.7$ (Fig. 6A); at $\varphi$

$386>0.8$, strong particle networks gave the suspension sufficient strength to arrest all bubbles with $y<$

387 1. Therefore, bubble trapping may have been enhanced by the smooth experiment walls, which 388 allowed bubble expansion to be accommodated by the cap sliding upwards. However, bubble 
buoyancy force $(<0.6 \mathrm{~N}$, Fig. 6C) generated a stress on the base of the cap of up to $1200 \mathrm{~Pa}$, which was much greater than the suspension yield strengths $(\ll<100 \mathrm{~Pa}$ based on rotational rheometry; e.g. Mueller et al., 2009, 2011; Tran et al. 2015; Fig. 3), suggesting that bubbles should not have been trapped. The lateral spreading of the bubble may explain this discrepancy. Lateral spreading was driven by deceleration of the bubble nose as it reached the more resistant (and slightly less dense) cap while its base continued to rise in the less viscous pure liquid below. The resulting thinning of the down-flowing annulus of fluid around the bubble reduces the yield stress (relative to

396 the buoyancy stress) required to trap a bubble indefinitely (Dubash and Frigaard, 2004).

397 Furthermore, complete spreading of the bubble to fill the tube below the cap generated horizontal 398 layers; thus gas ascent through the denser cap requires a Rayleigh-Taylor instability of a wavelength 399 limited by the tube diameter (Seropian et al, 2018). Therefore, bubble rise may depend more on the 400 deformation of the cap under its own weight.

401 Yield strength, consistency, and shear-thinning increase with $\varphi$ (Figure 3). In some experiments, a vertical increase in particle fraction within the cap caused rising bubbles to decelerate and change regime; we classified these as hybrid regimes. Bubble entrapment within the cap occurred over a wide range of average $\varphi$ (Figure 6), which suggests that either (1) the top of these caps achieved $\varphi>$ 0.8 whereupon bubbles became trapped regardless of cap thickness, or (2) the feedback between energy loss during bubble rise and increase in $\varphi$ was sufficient to trap bubbles even if $\varphi<0.8$. In this

407 scenario, bubble expansion was insufficient to maintain stress on the cap, such that the apparent 408 viscosity increased and bubbles decelerated until the stress applied by the bubbles fell below the 409 cap's yield strength and/or the bubbles spread laterally to fill the tube. Therefore, the coupled effect 410 of a shear-dependent viscous response and increasing $\varphi$ near the surface may be an effective 411 mechanism to trap bubbles in the cap. 
6.1. Flow regimes in near-surface magma

414 The near-surface basaltic magma at Stromboli contains $45-55$ vol\% phenocrysts (Landi et al., 2004;

415 Metrich et al., 2010). Rheological investigations of synthetic basalts observe the onset of yield 416 strength at 20-40 vol\% crystals (e.g. Philpotts et al., 1999; Jerram et al., 2003; Picard et al., 2013);

417 experiments on andesites show that bubbles begin to deform and connect at 20 vol\% crystallinity

418 (Lindoo et al., 2017). These values suggest that Strombolian magma is likely within or above the 419 crystallinity range for the deformed bubble regime.

420 Our experiments in the deformed regime had pulsatory bubble burst events that lasted longer and decayed more slowly than in the slug regime (Figure 9) and produced small clasts that fountained above the surface (supplementary video 2). These characteristics may reflect smaller burst apertures that vibrate as gas is released. With increasing $\varphi$, bubble deformation increases (Oppenheimer et al., 2015), hence the bubble aperture is likely to decrease and generate bubble bursts with higher frequency and more gradual gas release (Fig. 9). By comparison, eruptions during normal activity at Stromboli are pulsatory (Taddeucci et al., 2013; Gaudin et al., 2014), last up to tens of seconds (Houghton et al., 2016), have an abrupt start and slow decay (Gaudin et al., 2014), and are accompanied by pyroclast fountains hundreds of meters high. These characteristics are consistent with a highly deformed bubble regime.

\subsection{Variability of normal activity}

431 The experimental regime transitions occur over a small range of particle fractions ( 17 vol\% from 432 the onset of side flow to RCP). Hence small variations in solid fraction may cause significant transitions in gas migration regimes. At Stromboli, the NE vent typically has short, loud and ballisticgenerating eruptions (type 1 events) relative to the long, pulsatory, complex ash-generating eruptions from the SW vent (type 2 events; Ripepe and Marchetti, 2002; Harris and Ripepe, 2007a). 
complex pulsatory acoustic signals of lower amplitude (Figure 9). This resembles the description for

438 eruptions from the SW vent, consistent with observations that magma in the SW vent is more 439 crystalline (Landi et al., 2011). In contrast, puffing occurs at hotter (lower crystallinity) vents (Landi 440 et al., 2011). We therefore suggest that variations in crystallinity may cause spatial and temporal 441 variations in activity.

\subsection{Slug model vs Plug model}

443 There is growing evidence that the slug model for Strombolian eruptions requires modification to 444 account for crystal-rich near-surface magma. Alternative models suggest rupture of a crystal-rich 445 plug as a source mechanism (Gurioli et al., 2014; Suckale et al., 2016). Here bubbles accumulate 446 under the plug until (1) the bubble pressure causes the plug to rupture or (2) the plug becomes 447 gravitationally unstable, and the bubble pressure is suddenly released to the surface.

448 The near-surface crystal-bearing magma at Stromboli is likely deeper $(0.8 \mathrm{~km}$ and $2-4 \mathrm{~km}$ depth; 449 Landi et al., 2004; Metrich et al., 2010; Agostini et al., 2013) than the onset of rapid (non450 equilibrium) bubble expansion ( $\gamma>1$; James et al., 2008; Del Bello et al., 2012), which is estimated to 451 begin at $\leq 100 \mathrm{~m}$ below the crater (Del Bello et al., 2012). In such a case, bubbles reach the cap with $\gamma$ $452<1$, and rapid expansion begins when the bubble is already in the crystal-rich layer. This condition 453 means that bubble rise occurs in a deformed (or other crystal-rich) regime and models predicting 454 overpressure must consider irregular bubble rise in non-Newtonian suspensions. Additionally, if $\gamma<1$ 455 when the bubble reaches the crystal-rich layer, bubble entrapment may occur either beneath or within that layer. In our experiments with $\gamma<1$, bubble entrapment is related to yield strength. Since basalts can develop yield strengths at $20-40$ vol\% crystals (e.g. Philpotts et al., 1999; Picard et al., 2013), even moderate crystallinities at depth can trap bubbles. Therefore, breaching the cap may require external modifiers such as tectonic stresses and/or modified rheology and compressibility caused by a reservoir of small bubbles in the cap (Suckale et al., 2016). 
461 The crystal-rich layer can also enable the accumulation and coalescence of smaller bubbles into

462 conduit-sized bubbles that eventually rise through the plug (Belien et al., 2010; Suckale et al., 2016;

463 Barth et al., 2019). Furthermore, trapped bubbles can occur at any level in the crystal-rich magma.

464 Therefore, while the slug model depends on slow slug formation and rapid slug rise such that only

465 one slug can rise in the conduit at any time, a model where bubbles can be trapped or delayed no

466 longer precludes simultaneous rise from depth of several bubbles. Indeed, magma levels in the

467 conduit appear to increase with gas flux (Ripepe et al., 2002), which may indicate increased bubble

468 entrapment.

469 When analyzed from an equilibrium perspective, gas compositions from normal Strombolian activity

470 suggest source depths of 0.8 and $2.7 \mathrm{~km}$ below the craters (Burton et al., 2007). While both source

471 depths may be within crystal-bearing ("high porphyritic") magma, the shallower source corresponds

472 to the estimated depth of the crystal-rich cap (Landi et al., 2004; Agostini et al., 2013), and is 473 associated with weaker eruptions (Burton et al., 2007). Our data suggest that these bubbles could

474 have been trapped or delayed in a crystal-rich plug. Importantly, bubbles change chemistry by

475 volatile exchange with the surrounding melt. Estimates of bubble source depths (e.g., Burton et al., 476 2007) assume equilibrium degassing at depth followed by sufficiently fast ascent to preserve the 477 deep gas signature. This leads to erroneous depth estimates if gas chemistry changed without 478 equilibrating during bubble entrapment or hindered ascent (Pichavant et al., 2013).

479 The likelihood of bubble entrapment in the Stromboli conduit suggests that a weak plug model is 480 reasonable. Importantly, many volcanoes that have Strombolian activity also have moderate-to-high 481 crystallinities. Investigating eruption behavior at other volcanoes alongside crystal textures may help 482 to constrain the role of crystals in Strombolian eruptions. For example, the 2000 eruption at Etna 483 volcano, Italy, alternated between lava fountains ( 35 vol\% crystals) and Strombolian eruptions (> 55 vol\%; Polacci et al., 2006; Giordano et al., 2010), as did activity during the 1943-1952 eruption of 
intermediate magma composition, Strombolian eruptions have lower crystallinity than (and

487 alternate with) Vulcanian eruptions (Wright et al., 2012). Cashman and Sparks (2013) show that

488 Strombolian and Vulcanian eruptions have similar ranges in crystallinity but differ mainly in melt viscosity. These data support the soft plug model for Strombolian eruptions where near-surface magmas have sufficiently high crystallinity to temporarily impede bubble rise, with stronger, more crystalline, less permeable plugs leading to a low-melt-viscosity equivalent of Vulcanian-style plug failure. At the other extreme are Strombolian eruptions formed by rise of individual large bubbles in crystal-poor lava lakes, such as Kilauea and Erebus (e.g. Gerst et al. 2013; Qin et al. 2018).

\section{Conclusions}

Most models for Strombolian eruptions ignore the effect of crystals on bubble rise. Here, we show that particles modulate the rise of conduit-filling bubbles, generating flow characteristics that depend on particle fraction and stress applied by the bubble on the cap.

If the gas bubbles expand slowly (low stress on the cap), particle-rich suspensions can efficiently trap large bubbles, allowing gas to accumulate below or within the cap before rising through the cap. This

500 is essentially a "weak plug" model. At Stromboli volcano, the crystal-bearing magma is deeper or of 501 similar depth to the onset of rapid (high stress) gas expansion. Therefore, Stromboli may have a weak plug.

503 During rapid gas expansion in a particle-rich suspension, bubbles are highly deformed, and therefore 504 burst at the surface through a small aperture. Gradual gas release through a vibrating aperture leads 505 to pulsatory fountains of clasts and longer acoustic signals of lower amplitude, which start abruptly 506 and decay slowly. Since burst aperture decreases at higher particle fraction, these features likely 507 become more pronounced as particle fraction increases. These observations fit with observations at 508 Stromboli volcano, suggesting that variations in explosion duration, pulsations, and fountaining may 509 provide insight into near-surface magma crystallinity. This research suggests that Strombolian 
eruptions are linked to near-surface crystallization, and that local/temporal variations in crystallinity or crystal-bubble interactions may explain variations in degassing style.

\section{Acknowledgements}

513 This research was funded by the People Programme (Marie Curie Actions) of the European Union's

514 Seventh Framework Programme (FP7/2007-2013) under the project NEMOH, REA grant agreement

515 number 289976. We would like to thank Einat Lev, Jon Blundy, Bettina Scheu, Marie Edmonds, and

516 Mike Kendall for helpful comments and insights, as well as Heidy Mader and Paul Jarvis for their help

517 with rheology concepts and measurements. We would also like to express our warm appreciation of insightful edits and reviews by Tamsin Mather, Lucia Gurioli, and an anonymous reviewer; unfortunately, due to length constraints we were unable to include all suggested additions.

\section{Supplementary videos}

521 Supplementary video 1 shows bubble rise and burst in an experiment in the slug flow regime $(\varphi=$ bubble injection in the experiment.

Supplementary video $2 \mathrm{a}$ shows bubble rise in an experiment in the side flow regime, where bubble burst at the surface was more complex $(\varphi=0.82$; initial bubble volume $=49 \mathrm{~mL})$. The video is slowed

$5265 x$ and starts at bubble injection. Supplementary video $\mathbf{2 b}$ shows a close-up of the surface at burst.

527 Video is slowed 10x.

\section{Bibliography}

1. Agostini, C., A. Fortunati, F. Arzilli, P. Landi, and M. R. Carroll (2013), Kinetics of crystal evolution as a probe to magmatism at Stromboli (Aeolian Archipelago, Italy), Geochim. Cosmochim. Acta, 110, 135 - 151, doi:10.1016/j.gca.2013.02.027. 
3. Bagdassarov, N. (1994). Pressure and volume changes in magmatic systems due to the vertical displacement of compressible materials. Journal of Volcanology and Geothermal Research, 63(12):95-100.

4. Barberi, F., Rosi, M., and Sodi, A. (1993). Volcanic hazard assessment at Stromboli based on review of historical data. Acta Vulcanologica. 3, 173-187.

5. Barth, A., Edmonds, M., and Woods, A. (2019). Valve-like dynamics of gas flow through a packed crystal mush and cyclic strombolian explosions. Nature Scientific Reports, 9, 821. DOI: 10.1038/s41598-018-37013-8

6. Beckett, F. M., Burton, M., Mader, H. M., Phillips, J. C., Polacci, M., Rust, A. C., and Witham, F. (2014). Conduit convection driving persistent degassing at basaltic volcanoes. Journal of Volcanology and Geothermal Research, 283:19-35.

7. Belien, I. B., Cashman, K. V., and Rempel, A. W. (2010). Gas accumulation in particle-rich suspensions and implications for bubble populations in crystal-rich magma. Earth and Planetary Science Letters, 297(1-2):133-140.

8. Blackburn, E. A., Wilson, L., and Sparks, R. S. J. (1976). Mechanisms and dynamics of strombolian activity. Journal of the Geological Society, 132(4):429-440.

9. Brown, E., Zhang, H. J., Forman, N. A., Maynor, B. W., Betts, D. E., DeSimone, J. M., and Jaeger, H. M. (2011). Shear thickening and jamming in densely packed suspensions of different particle shapes. Physical Review E, 84(3):11.

10. Burton, M., Allard, P., Mure, F., and La Spina, A. (2007). Magmatic gas composition reveals the source depth of slug-driven strombolian explosive activity. Science, 317(5835):227-230.

11.Capponi, A., James, M. R., and Lane, S. J. (2016). Gas slug ascent in a stratified magma: Implications of flow organisation and instability for strombolian eruption dynamics. Earth and Planetary Science Letters, 435:159-170.

12.Capponi, A., Lane, S., and James, M. (2017). The implications of gas slug ascent in a stratified magma for acoustic and seismic source mechanisms in strombolian eruptions. Earth and Planetary Science Letters, 468: 101-111, https://doi.org/10.1016/j.epsl.2017.04.008.

13.Caricchi, L., Burlini, L., Ulmer, P., Gerya, T., Vassalli, M., and Papale, P. (2007). Non-Newtonian rheology of crystal-bearing magmas and implications for magma ascent dynamics. Earth and Planetary Science Letters, 264(3-4):402-419.

14.Cashman, K. V. and Sparks, R. S. J. (2013). How volcanoes work: A 25 year perspective. Geological Society of America Bulletin, 125(5-6):664-690.

15.Castruccio, A., Rust, A. C., and Sparks, R. S. J. (2010). Rheology and flow of crystal-bearing lavas: Insights from analogue gravity currents. Earth and Planetary Science Letters, 297(3-4):471-480.

16.Chouet, B., Dawson, P., Ohminato, T., Martini, M., Saccorotti, G., Giudicepietro, F., De Luca, G., Milana, G., and Scarpa, R. (2003). Source mechanisms of explosions at Stromboli volcano, Italy, determined from moment-tensor inversions of very-long-period data. Journal of Geophysical Research Solid Earth, 108(B1). 
17.Conte, A. M., C. Perinelli, and R. Trigila (2006), Cooling kinetics experiments on different Stromboli lavas: Effects on crystal morphologies and phases composition, J. Volcanol. Geotherm. Res., 155(3-4), 179-200, doi:10.1016/j.jvolgeores.2006.03.025.

18.Del Bello, E., Lane, S. J., James, M. R., Llewellin, E. W., Taddeucci, J., Scarlato, P., and Capponi, A. (2015). Viscous plugging can enhance and modulate explosivity of strombolian eruptions. Earth and Planetary Science Letters, 423:210-218.

19.Del Bello, E., Llewellin, E. W., Taddeucci, J., Scarlato, P., and Lane, S. J. (2012). An analytical model for gas overpressure in slug-driven explosions: Insights into strombolian volcanic eruptions. Journal of Geophysical Research-Solid Earth, 117.

20.Edwards, M. J., Pioli, L., Andronico, D., Scollo, S., Ferrari, F., Cristaldi, A. (2018) Shallow controlling factors on the explosivity of basaltic magmas: The May 17-25 eruption of Etna volcano (Italy). JVGR, doi:10.1016/j.jvolgeores.2018.05.015

21.Erlund, E.J., Cashman K.V., Wallace, P.J., Pioli, L., Rosi, M., Johnson E., Delgado Granados H. (2010). Compositional evolution of magma from Parícutin Volcano, Mexico: The tephra record. Journal of Volcanology and Geothermal Research, 167-187. DOI: $\underline{10.1016 / j . j v o l g e o r e s .2009 .09 .015}$

22.Francis, P., Oppenheimer, C., and Stevenson, D. (1993). Endogenous growth of persistently active volcanoes. Nature, 366(6455):554-557.

23. Gaudin, D., Taddeucci, J., Scarlato, P., Moroni, M., Freda, C., Gaeta, M., and Palladino, D. M. (2014). Pyroclast tracking velocimetry illuminates bomb ejection and explosion dynamics at Stromboli (Italy) and Yasur (Vanuatu) volcanoes. Journal of Geophysical Research-Solid Earth, 119(7):5384-5397.

24.Gaudin, D., J. Taddeucci, P. Scarlato, E. del Bello, T. Ricci, T. Orr, B. Houghton, A. Harris, S. Rao, and A. Bucci (2017). Integrating puf fi ng and explosions in a general scheme for Strombolianstyle activity, J. Geophys. Res. Solid Earth, 122, 1860 - 1875, doi:10.1002/2016JB013707.

25.Gerst, A., M. Hort, R. C. Aster, J. B. Johnson, and P. R. Kyle (2013), The first second of volcanic eruptions from the Erebus volcano lava lake, Antarctica-Energies, pressures, seismology, and infrasound, J. Geophys. Res. Solid Earth, 118, 3318-3340, doi:10.1002/jgrb.50234

26.Giordano, D., Polacci, M., Papale P., and Caricchi, L. (2010). Rheological control on the dynamics of explosive activity in the 2000 summit eruption of Mt. Etna, Solid Earth, 1: 61-69.

27.Gurioli, L., Colo, L., Bollasina, A. J., Harris, A. J. L., Whittington, A., and Ripepe, M. (2014). Dynamics of strombolian explosions: Inferences from field and laboratory studies of erupted bombs from Stromboli volcano. Journal of Geophysical Research-Solid Earth, 119(1):319-345.

28. Harris, A. and Ripepe, M. (2007a). Synergy of multiple geophysical approaches to unravel explosive eruption conduit and source dynamics - a case study from Stromboli. Chemie Der ErdeGeochemistry, 67(1):1-35.

29. Harris, A., and M. Ripepe (2007b), Temperature and dynamics of degassing at Stromboli, J. Geophys. Res., 112, B03205, doi:10.1029/2006JB004393

30.Harris, A. J. L., Delle Donne, D., Dehn, J., Ripepe, M., and Worden, A. K. (2013). Volcanic plume and bomb field masses from thermal infrared camera imagery. Earth and Planetary Science Letters, 365:77-85. 
31. Hasan, A. H., Mohammed, S. K., Pioli, L., Hewakandamby, B. H., Azzopardi, B. J. (2019). Gas rising through a large diameter column of very viscous liquid: Flow patterns and their dynamics characteristics. International Journal of Multiphase Flow. 116, 1-14.

32. Herschel, W. H. and Bulkley, R. (1926). Konsistenzmessungen von gummi-benzoll"osungen. Kolloid-Zeitschrift, 39(4):291-300.

33. Hoover, S. R., Cashman, K. V., and Manga, M. (2001). The yield strength of subliquidus basalts experimental results. Journal of Volcanology and Geothermal Research, 107(1-3):1-18.

34. Houghton, B. F., Taddeucci, J., Andronico, D., Gonnermann, H. M., Pistolesi, M., Patrick, M. R., Orr, T. R., Swanson, D. A., Edmonds, M., Gaudin, D., Carey, R. J., and Scarlato, P. (2016). Stronger or longer: Discriminating between hawaiian and strombolian eruption styles. Geology, 44(2):163166.

35.James, M. R., Lane, S. J., and Chouet, B. A. (2006). Gas slug ascent through changes in conduit diameter: Laboratory insights into a volcano-seismic source process in low-viscosity magmas. Journal of Geophysical Research-Solid Earth, 111(B5).

36.James, M. R., Lane, S. J., and Corder, S. B. (2008). Modelling the rapid near-surface expansion of gas slugs in low-viscosity magmas. Geological Society, London, Special Publications, 307(1):147167.

37.James M.R., Lane S.J., Wilson L., and Corder S.B. (2009). Degassing at low magma-viscosity volcanoes: Quantifying the transition between passive bubble-burst and Strombolian eruption. Journal of Volcanology and Geothermal Research, 180. 81-88.

38.James, M. R., Lane, S. J., and Houghton, B. F. (2013). Unsteady explosive activity. In Fagents, S. A., Gregg, T. K. P., and Lopes, R. M. C., editors, Modeling Volcanic Processes, pages 107-128. Cambridge University Press.

39.Jerkins, M., Schroter, M., Swinney, H. L., Senden, T. J., Saadatfar, M., and Aste, T. (2008). Onset of mechanical stability in random packings of frictional spheres. Physical Review Letters, 101(1).

40.Jerram, D. A., Cheadle, M. J., and Philpotts, A. R. (2003). Quantifying the building blocks of igneous rocks: Are clustered crystal frameworks the foundation? Journal of Petrology, 44(11):2033-2051.

41.La Felice, S., and Landi, P. (2011). A spatter-forming, large-scale paroxysm at Stromboli Volcano (Aeolian Islands, Italy): insight into magma evolution and eruption dynamics. Bulletin of Volcanology, 73(9), 1393-1406. Doi: 10.1007/s00445-011-0476-x

42.Landi, P., Marchetti, E., La Felice, S., Ripepe, M., and Rosi, M. (2011). Integrated petrochemical and geophysical data reveals thermal distribution of the feeding conduits at Stromboli volcano, italy. Geophysical Research Letters, 38.

43.Landi, P., Metrich, N., Bertagnini, A., and Rosi, M. (2004). Dynamics of magma mixing and degassing recorded in plagioclase at Stromboli (aeolian archipelago, Italy). Contributions to Mineralogy and Petrology, 147(2):213-227.

44.Lane, S. J., James, M. R., and Corder, S. B. (2013). Volcano infrasonic signals and magma degassing: First-order experimental insights and application to Stromboli. Earth and Planetary Science Letters, 377:169-179. 
45. Lautze, N. C., Houghton, B. F. (2005). Physical mingling of magma and complex eruption dynamics in the shallow conduit at Stromboli volcano, Italy. Geology, 33(5), 425-428. Doi: $10.1130 / G 21325.1$

46.Leduc, L., Gurioli, L., Harris, A., Colo, L., and Rose-Koga, E. F. (2015). Types and mechanisms of strombolian explosions: characterization of a gas-dominated explosion at Stromboli. Bulletin of Volcanology, 77(1).

47.Lindoo A., Larsen J. F., Cashman K. V., Oppenheimer J. (2017) Crystal controls on permeability development and degassing in basaltic andesite magma. Geology, 45 (9), $831-834$.

48. Mader, H. M., Llewellin, E. W., and Mueller, S. P. (2013). The rheology of two-phase magmas: A review and analysis. Journal of Volcanology and Geothermal Research, 257:135-158.

49. Metrich, N., Allard, P., Aiuppa, A., Bani P., Bertagnini A., Shinohara H., Parello F., Di Muro A., Garaebiti E., Belhadj O., Massare D (2011). Magma and Volatile Supply to Post-collapse Volcanism and Block Resurgence in Siwi Caldera (Tanna Island, Vanuatu Arc). Journal of petrology 52(6), 1077-1105.

50. Metrich, N., Bertagnini, A., and Di Muro, A. (2010). Conditions of magma storage, degassing and ascent at Stromboli: New insights into the volcano plumbing system with inferences on the eruptive dynamics. Journal of Petrology, 51(3):603-626.

51.Moitra, P. and Gonnermann, H. M. (2015). Effects of crystal shape- and size-modality on magma rheology. Geochemistry Geophysics Geosystems, 16(1):1-26.

52.Mueller, S., Llewellin, E. W., and Mader, H. M. (2009). The rheology of suspensions of solid particles. Proceedings of the Royal Society a-Mathematical Physical and Engineering Sciences, 466(2116):1201-1228.

53. Mueller, S., Llewellin, E. W., and Mader, H. M. (2011). The effect of particle shape on suspension viscosity and implications for magmatic flows. Geophysical Research Letters, 38:5.

54.Onoda, G. Y. and Liniger, E. G. (1990). Random loose packings of uniform spheres and the dilatancy onset. Physical Review Letters, 64(22):2727-2730.

55.Oppenheimer, J., Rust, A., Cashman, K., and Sandnes, B. (2015). Gas migration regimes and outgassing in particle-rich suspensions. Frontiers in Physics, 3:60.

56.Palma, J. L., Blake, S., and Calder, E. S. (2011). Constraints on the rates of degassing and convection in basaltic open-vent volcanoes. Geochemistry Geophysics Geosystems, 12.

57.Patrick, M. R., Harris, A. J. L., Ripepe, M., Dehn, J., Rothery, D. A., and Calvari, S. (2007). Strombolian explosive styles and source conditions: insights from thermal (FLIR) video. Bulletin of Volcanology, 69(7):769-784.

Parfitt, E. A. (2004) A discussion of the mechanisms of explosive basaltic eruptions. Journal of Volcanology and Geothermal Research, 134 (102), 77-107.

58.Philpotts, A. R., Brustman, C. M., Shi, J. Y., Carlson, W. D., and Denison, C. (1999). Plagioclasechain networks in slowly cooled basaltic magma. American Mineralogist, 84(11-12):1819-1829. 
702

703

704

705

706

707

708

709

710

711

712

713

714

715

716

717

718

719

720

721

722

723

724

725

726

727

59.Picard, D., Arbaret, L., Pichavant, M., Champallier, R., and Launeau, P. (2013). The rheological transition in plagioclase-bearing magmas. Journal of Geophysical Research-Solid Earth, 118(4):1363-1377.

60.Pichavant, M., Di Carlo, I., Rotolo, S. G., Scaillet, B., Burgisser, A., Le Gall, N., and Martel, C. (2013). Generation of co2-rich melts during basalt magma ascent and degassing. Contributions to Mineralogy and Petrology, 166(2):545-561.

61.Polacci, M., Corsaro, R. A., and Andronico, D. (2006) Coupled textural and compositional characterization of basaltic scoria: Insights into the transition from Strombolian to fire fountain activity at Mount Etna, Italy. Geology. 34 (3): 201-204. doi: 10.1130/G22318.1

62. Qin, Z., Soldati, A., Santana, L. C. V., Rust, A. C., Suckale, J., \& Cashman, K. V. (2018). Slug stability in flaring geometries and ramifications for lava-lake degassing. Journal of Geophysical Research: Solid Earth.doi:10.1029/2018jb016113

63. Ripepe, M. and Marchetti, E. (2002). Array tracking of infrasonic sources at Stromboli volcano. Geophysical Research Letters, 29(22).

64. Ripepe, M., Harris A. J. L., Carniel R. (2002). Thermal, seismic and infrasonic evidences of variable degassing rates at Stromboli volcano. Journal of Volcanology and Geothermal Research, 118, 285297.

65. Ripepe, M., Marchetti, E., and Ulivieri, G. (2007). Infrasonic monitoring at stromboli volcano during the 2003 effusive eruption: Insights on the explosive and degassing process of an open conduit system. Journal of Geophysical Research-Solid Earth, 112(B9).

66. Rosi, M., Pistolesi, M., Bertagnini, A., Landi, P., Pompilio, M., \& Di Roberto, A. (2013). Chapter 14 Stromboli volcano, Aeolian Islands (Italy): present eruptive activity and hazards. Geological Society, London, Memoirs, 37(1), 473-490. doi:10.1144/m37.14

67.Seyfried, R., and Freundt, A., 2000, Experiments on conduit flow and eruption behaviour of basaltic volcanic eruptions. J. Geophys. Res., v. 105, no. B10, p. 727-740, doi:10.1029/2000JB900096

68.Suckale, J., Keller T., Cashman K. V., and Persson P.-O. (2016) Flow-to-fracture transition in a volcanic mush plug may govern normal eruptions at Stromboli, Geophys. Res. Lett., 43, $12071-$ 12081. doi:10.1002/2016GL071501.

69. Taddeucci, J., Palladino, D. M., Sottili, G., Bernini, D., Andronico, D., and Cristaldi, A. (2013). Linked frequency and intensity of persistent volcanic activity at Stromboli (Italy). Geophysical Research Letters, 40(13):3384-3388.

70.Tran, A., Rudolph, M. L., and Manga, M. (2015). Bubble mobility in mud and magmatic volcanoes. Journal of Volcanology and Geothermal Research, 294:11-24.

71.Vergniolle, S. (1998). Modeling two-phase flow in a volcano. 13th Australasian Fluid Mechanics Conference.

72. Viana, F., Pardo, R., Yanez, R., Trallero, J. L., and Joseph, D. D. (2003). Universal correlation for the rise velocity of long gas bubbles in round pipes. Journal of Fluid Mechanics, 494:379-398. 
73.von der Lieth, J. and Hort, M. (2016). Slug ascent and associated stresses during strombolian activity with non-Newtonian rheology. Journal of Geophysical Research: Solid Earth, 121(7):49234942.

74. White, E.T. and Beardmore R.H. (1962). The velocity of rise of single cylindrical air bubbles through liquids contained in vertical tubes. Chem. Eng. Sci. 17, 351-361.

75.Wright, H. M. N., Cashman, K. V., Mothes, P. A., Hall, M. L., Ruiz, A. G., and Le Pennec, J. L. (2012). Estimating rates of decompression from textures of erupted ash particles produced by 1999-2006 eruptions of Tungurahua volcano, Ecuador. Geology, 40(7):619-622. 